\title{
A Novel Approach to Hemangiopericytoma of the Sinonasal Cavity
}

\section{${ }^{1}$ Shruti Dhingra, ${ }^{2}$ Sandeep Bansal, ${ }^{1}$ Amit Shankar, ${ }^{3}$ Ashok K Gupta}

${ }^{1}$ Senior Resident, Department of ENT and Head and Neck Surgery, Postgraduate Institute of Medical Education and Research Chandigarh, India

${ }^{2}$ Assistant Professor, Department of ENT and Head and Neck Surgery, Postgraduate Institute of Medical Education and Research Chandigarh, India

${ }^{3}$ Professor and Head, Department of Otolaryngology and Head and Neck Surgery (Unit II), Postgraduate Institute of Medical Education and Research, Chandigarh, India

Correspondence: Ashok K Gupta, Professor and Head, Department of Otolaryngology and Head and Neck Surgery (Unit II) Postgraduate Institute of Medical Education and Research, Sector-12, Chandigarh-160012, India, Phone: 91-172-2747837 Fax: 91-172-2744401, 2747837, e-mail: drashokpgi@hotmail.com

\section{Abstract}

Hemangiopericytomas of the sinonasal cavity are relatively rare tumors. Most of them are essentially benign though malignant potential and metastasis to distant sites has also been reported. Treatment options usually involve external approaches. We hereby discuss the combined endoscopic and transoral approach to these tumors.

Keywords: Hemangiopericytoma, Vascular tumors, Sinonasal cavity, Endoscopic surgery.

\section{INTRODUCTION}

Hemangiopericytoma (HPC) is a rare angiogenic tumor, and less than 5\% of HPC occur in the sinonasal cavity. Most of these tumors are low metastatic potential, placing them in the category of essentially benign neoplasms. Because of the relative benign behavior of sinonasal HPC, to date, standard treatment regimens for these sinonasal tumors have been limited to wide-field extirpative approaches, usually via the lateral rhinotomy, Caldwell-Luc, or transfacial approaches. We present a case of complete endoscopic combined with transoral resection of a HPC.

\section{CASE REPORT}

A 43 years old male patient presented with complaints of swelling over the right cheek gradually increasing for the last 20 years with pain in the swelling for the last 1 year and history of oral bleed since the last 20 days. There was also history of loosening of teeth of the upper alveolus but no history of nasal
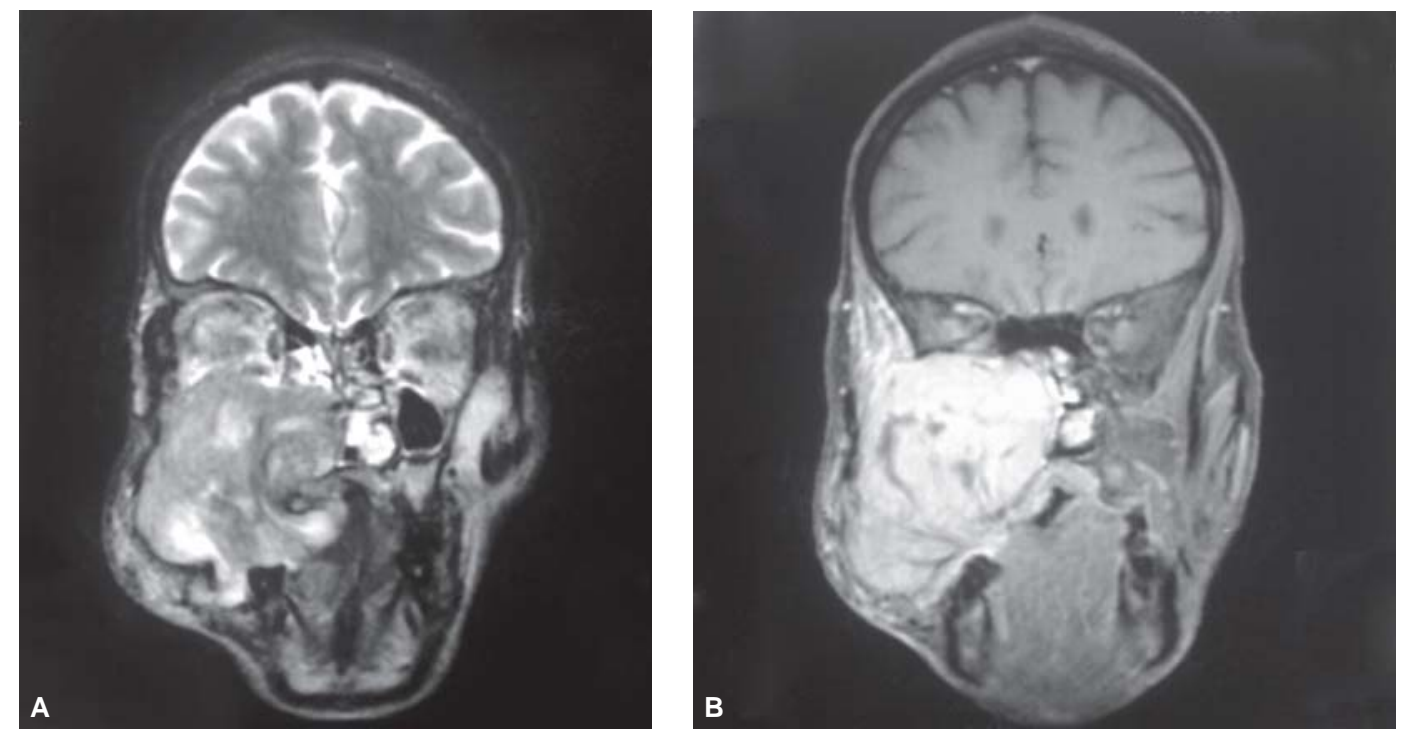

Figs $1 \mathrm{~A}$ and $\mathrm{B}$ : Coronal cuts showing heterogenous soft tissue density with extension into right maxillary sinus, anterior and posterior ethmoids, masticator space and palate 

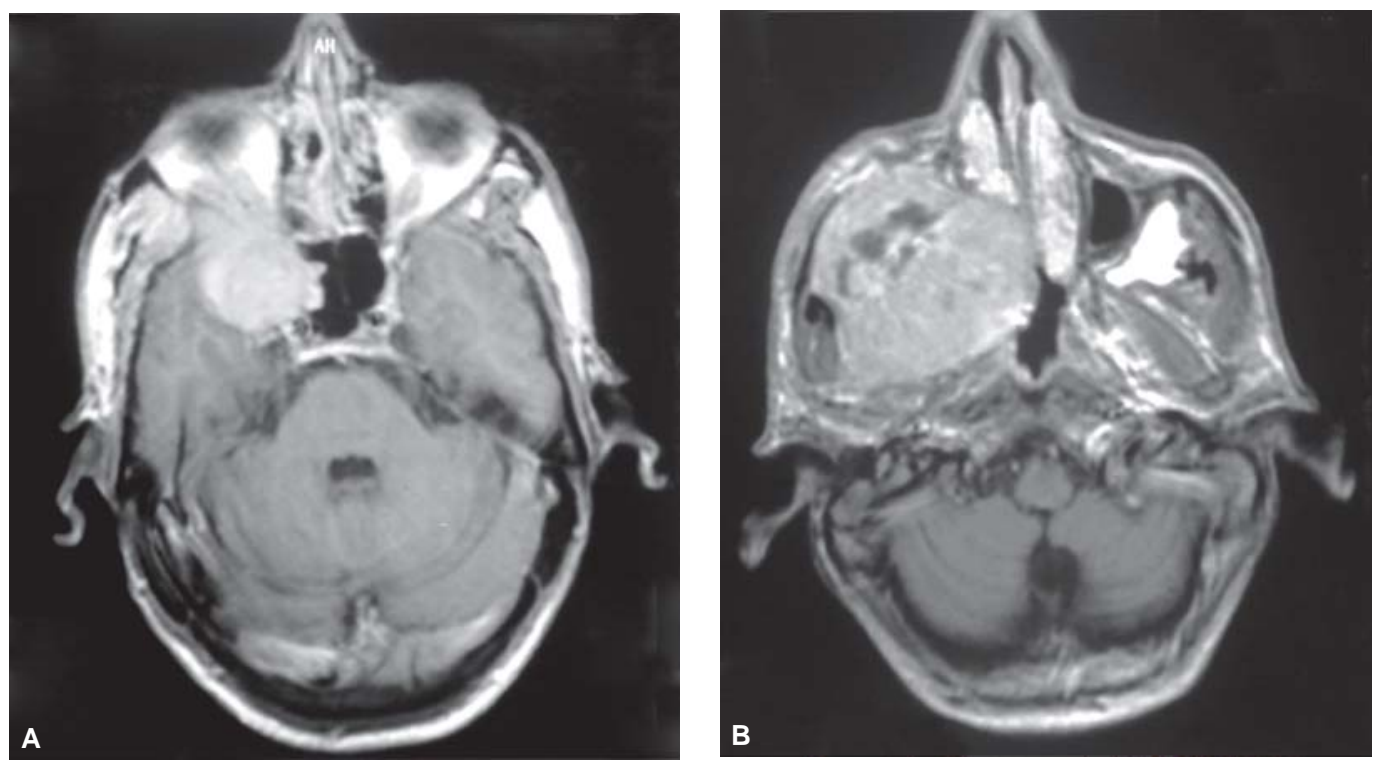

Figs 2A and B: Axial cuts showing extension into orbital apex, maxillary sinus, pterygopalatine space and infratemporal fossa

bleed or visual disturbance. On examination there was a diffuse nontender swelling $6 \times 8 \mathrm{~cm}$ over the right cheek extending from $2 \mathrm{~cm}$ below the right inferior orbital margin till the oral commissure. A proliferative growth was present in right upper alveolus extending from canine fossa to the retromolar trigone also involving the gingivolabial sulcus which was firm and bled on touch. No mass could be seen on anterior rhinoscopy. Magnetic Resonance Imaging revealed heterogenous soft tissue density involving right anterior, posterior ethmoids, maxillary sinus, pterygopalatine fossa, infratemporal fossa, masticator space, hard palate and orbital apex (Figs 1A to 2B). Histopathology confirmed the diagnosis of hemangiopericytoma. An endoscopic excision of the mass was done with clearence of the maxillary sinus, posterior ethmoids and sphenoids upto the orbital apex. Osteotomy cut was given at the right upper incisor and part of the upper alveolus was removed. The patient has been under our followup for the last one year with no locoregional recurrence.

\section{DISCUSSION}

HPC is an uncommon soft tissue neoplasm that arises from the pericytes of Zimmermann that function as baroreceptors within the outer portion of capillary walls. It constitutes approximately $1 \%$ of all angiogenic tumors. Though most common in the abdomen (pelvis, retroperitonium) and lower extremities, 15 to 20\% of HPC will occur in the head and neck. ${ }^{1}$ Within the head and neck the most common site being the sinonasal and oropharyngeal cavities. ${ }^{2}$

There is no known sex or race predominance, and most cases occur in patients of third to fifth decades. ${ }^{3}$ Clinically, sinonasal HPC usually presents with nasal obstruction and bleeding. With increasing tumor size ophthalmologic findings of proptosis, epiphora, and diplopia may occur. These symptoms maybe present for years before presentation. Clinically one sees a unilateral rubbery polypoid nasal mass that may be soft or firm, and tan, gray, whitish, or vascular in appearance. Multiple lesions are uncommon. ${ }^{4}$ No outward sign of the vascular nature of the tumor is evident, except for the occasional finding of a few overlying dilated vascular spaces. Typically, it is not noticed unless it causes nasal obstruction or becomes visible on a mucosal surface such as palatine mucosa. ${ }^{5}$ Regional lymph node involvement is rare. At initial presentation they are frequently mistaken for nasal polyps. Other differentials include a variety of other benign vascular tumors such as pyogenic granuloma, angiofibroma, and leiomyoma as well as the malignant fibrous histiocytomas and synovial sarcomas.

CT imaging demonstrates a unilateral noncalcified soft tissue mass that may displace adjacent structures or erode bone. Obstructed adjacent sinuses may be opacified. The vascular nature will only be apparent on contrast enhanced images. MRI may show characteristic flow voids if the tumor is highly vascular.

Intranasal biopsy may be performed to secure a tissue diagnosis, but the vascular nature of the tumor may predispose to significant hemorrhage.

The pathological diagnosis of HPC can be elusive. The diagnosis of hemangiopericytoma is made by its characteristic architectural pattern and configuration in 
ultrastructural or immunohistochemical studies. ${ }^{6}$ Hemangiopericytomas are characterized by a typical architectural vascular pattern, "staghorn" or "antler-like", in association with tightly-packed round or spindle cells with plump nuclei and indistinct cytoplasm. ${ }^{7-9}$

The endothelial cells are demarcated sharply from the tumor cells by a periendothelial ring of reticulin fibers and a fine reticulin network may also surround the individual pericytes. ${ }^{8}$ Immunohistochemical findings typically reveal that vimentin is the only marker which is consistently expressed in hemangiopericytoma. ${ }^{6,10}$ Tumor cells have been rarely reported to express desmin as well as various neural markers such as S-100 protein and myelin-associated protein. ${ }^{6}$ The CD34 antigen is selectively associated with human hematopoietic progenitor cells and is expressed by vascular endothelial cells. ${ }^{11}$

With the exception of CD34, vascular markers (CD31 etc.) stain only the endothelial cells of the blood vessels. ${ }^{10}$ A silver reticulin stain is essential for light microscopy as this will blacken the capillary sheets, thus showing the extravascular position of the tumor cells. ${ }^{12}$

Up to $80 \%$ of hemangiopericytomas are malignant and $66 \%$ of these will eventually develop local or distant metastasis. ${ }^{6}$ The most common sites of metastasis include lungs, liver, bone, and regional lymph nodes. Grading has been related to the clinical course, with necrosis, nuclear atypia, high number of mitoses, and large tumor size (> $6.5 \mathrm{~cm}$ ) all correlating with poorer outcomes. ${ }^{13}$ The lesion typically enlarges slowly over a period of years, with expansile growth with smooth borders being more common than the infiltration of the surrounding tissues. The mainstay of management is wide surgical excision, as these tumors are relatively radioresistant. If a biopsy diagnosis is made, preoperative embolization may be helpful to reduce bleeding on resection. The natural history of these tumors is unpredictable. Both local recurrence and distant metastases have been seen years after a primary diagnosis. Chemotherapy and radiation therapy, have been used less commonly and their role remains controversial. Chemotherapy has met with very limited success. ${ }^{8}$ Most investigators therefore continue to advocate resection with wide margins as the therapy of choice. Recurrences usually occur greater than 5 years after surgery with the recurrence rate ranging from 9.5 to $50 \%$, depending on the length of follow-up. The literature also suggests that recurrences can be controlled with resection. ${ }^{14}$

Support for the endoscopic resection of sinonasal tumors is increasing. Characteristics of sinonasal HPC that make it suitable for endoscopic excision include its slow growth with expansion rather than infiltration that allows for endoscopic resection with negative margins. The magnification, illumination, and detailed image attainable with endoscopic instrumentation afford an accurate assessment of site of origin, margins, and surrounding structures that is superior to the view obtained by many of the standard approaches. The natural physiology of the nose may be preserved and injury to the lacrimal system may be avoided. The avoidance of an external incision is an added benefit. Similarly, for posteriorly based lesions, preoperative embolization of the internal maxillary artery system may limit operative blood loss and allows for safe, complete endoscopic resection. However, lesions with obvious extranasal extension should not be approached endoscopically, because margins would be difficult to obtain. It is of utmost importance to carefully select cases suitable for endoscopic resection in order to maximize the surgical advantages of the endoscope while avoiding the potential difficulties of bleeding and inadequate margins. Endoscope is also an essential tool for follow-up of these patients especially to recognize asymptomatic early recurrences. Life-long follow-up should be observed given the potential for recurrence even at 25 years.

\section{CONCLUSION}

Hemangiopericytomas are relatively uncommon vascular tumors of which clinical behavior is difficult to predict and the patients need to be followed up closely for an extended period. Histopathological diagnosis is based on special immunohistochemical staining techniques. Surgical excision still remains the treatment of choice.

\section{REFERENCES}

1. Batsakis J. Tumors of the head neck: Clinical and pathological considerations (2nd ed). Baltimore: Williams and Wilkins, 1979;307-12.

2. Lin JC, Hsu CY, Jan JS, Chen JT. Malignant hemangiopericytoma of the floor of the mouth: Report of a case and review of the literature. J Oral Maxillofac Surg 1996;54:1020-23.

3. Enzinger FM, Smith BH. Hemangiopericytoma: An analysis of 106 cases. Human Pathol 1976;7:61-82.

4. Del Gaudio JM, Garetz SL, Bradford CR, Stenson KM. Hemangiopericytoma of the oral cavity. Otolaryngol Head Neck Surg 1996;114:339-40.

5. Florence SM, Willard CC, Palian CW. Hemangiopericytoma of the buccal region: A case report. J Oral Maxillofac Surg 2001;59:449-53.

6. Sikes JW, Ghali GE, Veillon DM, Buchhinder D. Parotid mass in a 62 years old man. J Oral Maxillofac Surg 2003;61: 1073-77.

7. Serrano E, Coste A, Percodani J, Herve S, Brugel L. Endoscopic sinus surgery for sinonasal hemangiopericytomas. J Laryngol Otol 2002;116:951-54. 
8. Morita N, Yabuta T, Todo K, Taenaka Y. A metastatic hemangiopericytoma of the floor of the mouth. Int $\mathrm{J}$ Oral Maxillofac Surg 2006;35:563-65.

9. Alabdulhadi K, Burezg H, Nguyen V, Bernard C, Manoukian JJ. Extensive tongue hemangiopericytoma in a child: Modified combined modality of treatment to preserve well-functioning tongue. Int J Ped Otorhinol 2004;68:211-19.

10. Petrone G, Perrotti V, Fioroni M, Rubini C, Piattelli A. Hemangiopericytoma of the maxillary gingiva: Report of a case. J Clin Periodontol 2005;32:921-24.
11. Florence SM, Willard CC, Palian CW. Hemangiopericytoma of the buccal region: A case report. J Oral Maxillofac Surg 2001;59:449-53.

12. Goldwasser MS, Daw JL. Hemangiopericytoma of the palate: Case report. J Oral Maxillofac Surg 1990;48:211-15.

13. Enzinger FM, Smith BH. Hemangiopericytomas: An analysis of 106 Cases. Hum Patho1 1976;7:61-82.

14. El-Naggar AK, Batsakis JG, Garcia GM, et al. Sinonasal hemangiopericytomas. Arch Otolaryngol Head Neck Surg 1992;118:134-37. 